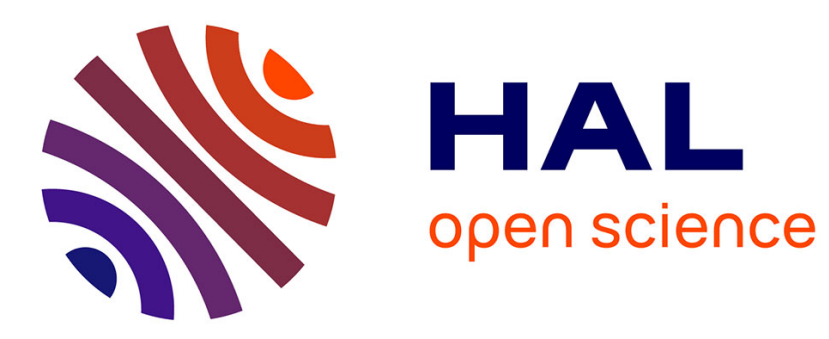

\title{
Anodic bonding using SOI wafer for fabrication of capacitive micromachined ultrasoonic transducers
}

Mohamed Bellaredj, Gilles Bourbon, Vincent Walter, Patrice Le Moal, Marc Berthillier

\section{- To cite this version:}

Mohamed Bellaredj, Gilles Bourbon, Vincent Walter, Patrice Le Moal, Marc Berthillier. Anodic bonding using SOI wafer for fabrication of capacitive micromachined ultrasoonic transducers. Journal of Micromechanics and Microengineering, 2014, 24, pp.025009. 10.1088/0960-1317/24/2/025009 . hal-01073836

\section{HAL Id: hal-01073836 https://hal.science/hal-01073836}

Submitted on 10 Oct 2014

HAL is a multi-disciplinary open access archive for the deposit and dissemination of scientific research documents, whether they are published or not. The documents may come from teaching and research institutions in France or abroad, or from public or private research centers.
L'archive ouverte pluridisciplinaire HAL, est destinée au dépôt et à la diffusion de documents scientifiques de niveau recherche, publiés ou non, émanant des établissements d'enseignement et de recherche français ou étrangers, des laboratoires publics ou privés. 


\section{Anodic bonding using SOI wafer for fabrication of capacitive micromachined ultrasonic transducers}

M. Bellaredj, G. Bourbon, V. Walter, P. Le Moal and M. Berthillier

5 FEMTO-ST,

Département Mécanique Appliquée

24, Rue de l'Epitaphe, 25000 Besançon France.

10 
Abstract. In medical ultrasound imaging, mostly piezoelectric crystals are used as ultrasonic transducers. Capacitive Micromachined Ultrasonic Transducers (CMUTs) introduced around 1994 have been shown to be a good alternative to conventional piezoelectric transducers in various aspects, such as sensitivity, transduction efficiency or bandwidth. This paper focuses on a fabrication process for CMUTs using anodic bonding of a SOI wafer on a glass wafer. The processing steps are described leading to a good control of the mechanical response of the membrane. This technology makes possible the fabrication of large membranes and can extend the frequency range of CMUTs to lower frequencies of operation. Silicon membranes having radii of $50 \mu \mathrm{m}, 70 \mu \mathrm{m}, 100 \mu \mathrm{m}$ and $150 \mu \mathrm{m}$ and a $1.5 \mu \mathrm{m}$ thickness are fabricated and electromechanically characterized using an auto-balanced bridge impedance analyzer. Resonant frequencies from $0.6 \mathrm{MHz}$ to $2.3 \mathrm{MHz}$ and an electromechanical coupling coefficient around $55 \%$ are reported. The effects of residual stress in the membranes and uncontrolled clamping conditions are clearly responsible for the discrepancies between experimental and theoretical values of the first resonance frequency. The residual stress in the membranes is determined to be between $90 \mathrm{MPa}$ and $110 \mathrm{MPa}$. The actual boundary conditions are between the clamped condition and the simply supported condition, and can be modeled with a torsional stiffness of $2 \cdot 10^{-7} \mathrm{~N} \cdot \mathrm{m} / \mathrm{rad}$ in the numerical model. 


\section{Introduction}

Capacitive Micromachined Ultrasonic Transducers were introduced in 1994 as an alternative to lead zirconium titanate based transducers (Haller and Khuri Yakub 1994). CMUTs generally provide a wider bandwidth than current piezoelectric transducers. A CMUT is a capacitor structure composed of

5 a thin plate and a bottom electrode. The sensitivity and the frequency response of CMUTs are determined by the physical dimensions and the material properties. Therefore, a stringent process control is decisive for CMUT fabrication. The thickness and the lateral dimensions of the membrane determine the mechanical behavior like eigenfrequencies or mechanical impedance. The electrical behavior like collapse voltage or DC bias also depends on the thickness and the lateral dimensions of the membrane, as well as the cavity parameters like the gap and the lateral dimensions of the bottom electrode.

Two fabrication methods for CMUTs are mainly used (Khuri-Yakub and Oralkan 2011): sacrificial release process and wafer bonding process. Sacrificial release process is the subject of a large number of works (Haller and Khuri Yakub 1994, Ladabaum et al 1998, Knight et al 2004, Teston et al 2006).

It involves many steps increasing the failure rate and the fabrication cost, but it is possible to outsource the fabrication to a low cost and opened access multi-users process called MUMPs ${ }^{\mathrm{TM}}$ (Liu and Shandas 2009, Manzanares and Espinosa 2012). However, the sacrificial release process reveals some limitations in size tied to sticking problems occurring during the releasing step. To prevent the membrane from sticking, the geometrical parameters of the membrane have to be chosen properly (Haller and Khuri Yakub 1994, Ergun et al 2005, Salim et al 2012).

In the wafer bonding process, membranes are fabricated using thin silicon wafers or Silicon On Insulator wafers (SOI). This method ensures precise thickness of the membrane and requires fewer steps than the sacrificial release process. The simple wafer bonding requires high temperatures $(\sim 1000$ $\left.{ }^{\circ} \mathrm{C}\right)$ (Huang et al 2008, Wygant et al 2009). Because of these high temperatures, these techniques exclude the possibility of a monolithic integration of the electronic circuits. To make the integration of the electronic circuits possible, low temperature processes (lower than $500{ }^{\circ} \mathrm{C}$ ) have been developed. One of these processes uses a temperature of $400{ }^{\circ} \mathrm{C}$ to bond a SOI wafer on a Si wafer covered by an 
adhesion layer made of titanium (Tsuji et al 2010). Anodic bonding involving a glass wafer and a simple silicon wafer has also developed by Yamaner et al 2011 and Yamaner et al 2012 with a similar temperature.

This paper reports an original low-temperature fabrication technique for CMUTs based on anodic bonding of a SOI wafer on a glass wafer. With the proposed manufacturing process, it is possible to fabricate very accurate thickness determined by the device layer thickness of the SOI wafer. The process described in this paper leads to air transducers since the bottom electrode is not electrically isolated from the top electrode. This process has to be considered as a first step in a process development approach, leading to CMUTs suitable for immersion applications. In this first step, the goal is to fabricate cells with controlled dimensions in terms of radius, thickness of the membrane and active gap. The goal is also to investigate the influence of the membrane radius on the electromechanical behavior of the CMUT cells. The active gap between the bottom electrode and the membrane is determined during the process by both the cavity depth and the bottom electrode thickness. The cavity depth and the bottom electrode thickness are controlled respectively by the etching time during the wet etching and by the deposition time of the Gold bottom electrode. These parameters will thus influence the electromechanical response of the CMUT. This electromechanical response is measured with two experimental approaches related to two different measuring instruments: a laser vibrometer (POLYTEC) to detect the first eigenfrequency by frequency sweeping and an auto-balanced bridge impedance analyzer (AGILENT HP4294A) for the measurement of membranes impedance and admittance as a function of the frequency.

Finally, the difference between the experimental and theoretical eigenfrequencies is explained by the amount of residual stress in the membranes (between $90 \mathrm{MPa}$ and $110 \mathrm{MPa}$ ) and by boundary conditions falling between a clamped rim and a simply supported rim.

\section{Process flow and design}

The process flow (figure 1) can be summarized in three main steps as follows:

- Etching of the cavities and evaporation of the bottom electrodes on the glass wafer, 
- Anodic bonding of the glass wafer on the SOI wafer,

- Etching of the handle layer and the buried oxide layer of the SOI wafer.

(a)
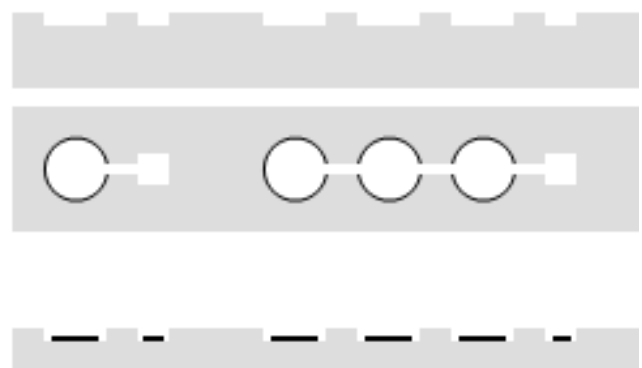

(b)

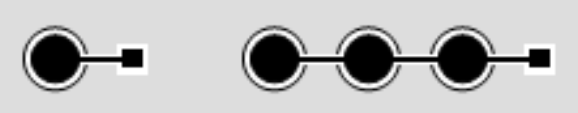

(c)

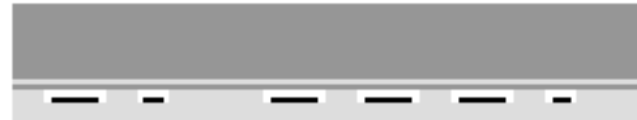

(d)

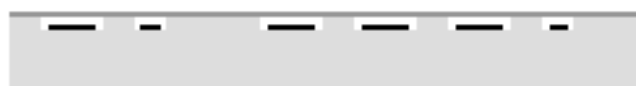

(e)

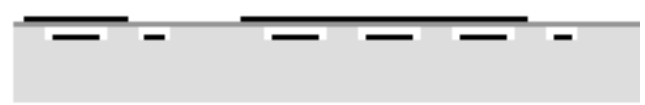

(f)

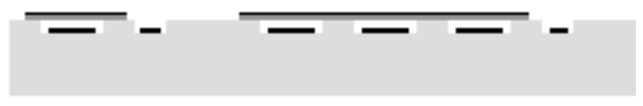

\section{Silica Silicon $\square$ Metal}

Figure 1. The process flow: (a) Etching of the cavity in the glass wafer, (b) Deposition of the bottom electrode by evaporation, (c) Anodic bonding of the glass wafer with the SOI wafer, (d) Etching of the silicon substrate and the buried oxide of the SOI, (e) Deposition of the top electrode by evaporation, (f) Dry etching of the access pad.

The glass wafer is a $520 \mu \mathrm{m}$ thick glass Pyrex 7740 substrate since Pyrex 7740 thermal expansion coefficient $\left(\approx 3 \cdot 2 \cdot 10^{-6} \mathrm{~K}^{-1}\right)$ is close to the silicon's one $\left(\approx 2 \cdot 6 \cdot 10^{-6} \mathrm{~K}^{-1}\right)$. The cavity etching step (figure

10 1-a) defines both the membrane radius and the gap height. The first photolithography step defines the cavity shape on the glass Pyrex 7740 substrate. The glass is etched in a buffered hydrofluoric acid solution through the photoresist. The ratio of ammonium fluoride $\left(\mathrm{NH}_{4} \mathrm{~F}\right)$ solution $\left(\mathrm{NH}_{4} \mathrm{~F} 40 \%\right)$ to 
hydrofluoric acid solution (HF 50\%) in this buffered hydrofluoric acid solution is 7:1. Finally, the first photoresist is removed to leave $1.35 \mu \mathrm{m}$ deep cavities. The bottom electrodes are fabricated by lift off technology (figure 1-b). The second photoresist is coated and patterned on the floor of the cavities and a $250 \mathrm{~nm}$ titanium-gold layer is evaporated. The second photoresist is removed before performing

5 bonding, leaving the bottom electrodes in the cavities. The bottom electrodes are not electrically isolated from the conductive membrane. Therefore the DC voltage applied to the membrane has to be controlled very precisely to avoid electrical shorting. The cavity depth and the electrode thickness result in an electrostatic gap around $1.1 \mu \mathrm{m}$. This value is quite large compared to usual values of gap but as mentioned earlier, one of the goals of this process is to investigate the influence of the membrane radius (between $50 \mu \mathrm{m}$ and $150 \mu \mathrm{m}$ ). The theoretical collapse voltage varies from $20 \mathrm{~V}$ for a $150 \mu \mathrm{m}$ membrane radius to $185 \mathrm{~V}$ for a $50 \mu \mathrm{m}$ membrane radius, with an electrostatic gap of 1.1 $\mu \mathrm{m} \pm 0.025 \mu \mathrm{m}$ RMS in both cases.

The membrane thickness is defined by the $1.5 \mu \mathrm{m}$ silicon device layer of the SOI wafer (figure 1-c). Both SOI wafer and processed Pyrex 7740 wafer are cleaned and surface activated before anodic

15 bonding. The contact is operated at ambient temperature, and then the coupled wafers are heated to $350{ }^{\circ} \mathrm{C}$, previously to the electrical bonding procedure. The release of the membranes is achieved (figure 1-d) by removing the handle layer using potassium hydroxide $(\mathrm{KOH})$ wet etching and then the buried oxide layer of the SOI wafer using the buffered hydrofluoric acid (BHF) wet etching previously mentioned. The buried oxide layer first protects the silicon membrane from $\mathrm{KOH}$ solution before 20 being removed in the buffered hydrofluoric acid solution. The Aluminum top electrode is deposited and wet etched in the third photoresist level (figure 1-e). The last step (figure 1-f) is a silicon dry etching, using aluminum as a hard mask, to get access to the pad. Like for all type of MEMS, the layout design and the process flow are conjointly designed. As an example, the thickness, related to the process, and the radius, related to the layout design, are the parameters controlling the value of the 25 first eigenfrequency. In our design, since a $1.5 \mu \mathrm{m}$ membrane thickness is chosen, the different membrane radii are determined so that the eigenfrequencies will be in the expected frequency range, i.e. $250 \mathrm{kHz}$ to $2.5 \mathrm{MHz}$. Using finite element simulation (ANSYS) in order to take into account anisotropic mechanical properties of silicon, four membranes radii of $50 \mu \mathrm{m}, 70 \mu \mathrm{m}, 100 \mu \mathrm{m}$ and 150 
$\mu \mathrm{m}$ are chosen, resulting in first mode theoretical eigenfrequencies between $250 \mathrm{kHz}$ and $2.3 \mathrm{MHz}$. It can be reminded that the numerical simulations firstly assume that membranes are free-stressed circular plates with a perfectly clamped rim.

The CMUT operating mode is enhanced near the collapse. For this reason, all the geometric 5 parameters are chosen to induce a maximal collapse voltage lower than $200 \mathrm{~V}$ for safety reasons. Indeed, the maximal collapse voltage defined by the lower radius, i.e. $50 \mu \mathrm{m}$, is $185 \mathrm{~V}$ for a $1.5 \mu \mathrm{m}$ thick membrane and a $1.1 \mu \mathrm{m}$ gap height. This choice leads to a theoretical collapse voltage of $20 \mathrm{~V}$ for the $150 \mu \mathrm{m}$ radius membrane.

Two types of design are investigated: unit cells (figure 2a) and a square lattice of $13 \times 13$ cells (figure

10 2b). Unit cells are perfectly decoupled from the surrounding structures by wide interspaces. The square lattice of unit cells has smaller interspaces with a total capacitance of $20 \mathrm{pF}$. A hexagonal lattice would give better performance in terms of pressure output, but the square lattice is only dedicated to capacitance measurement and the output pressure level will not be investigated in this paper. 


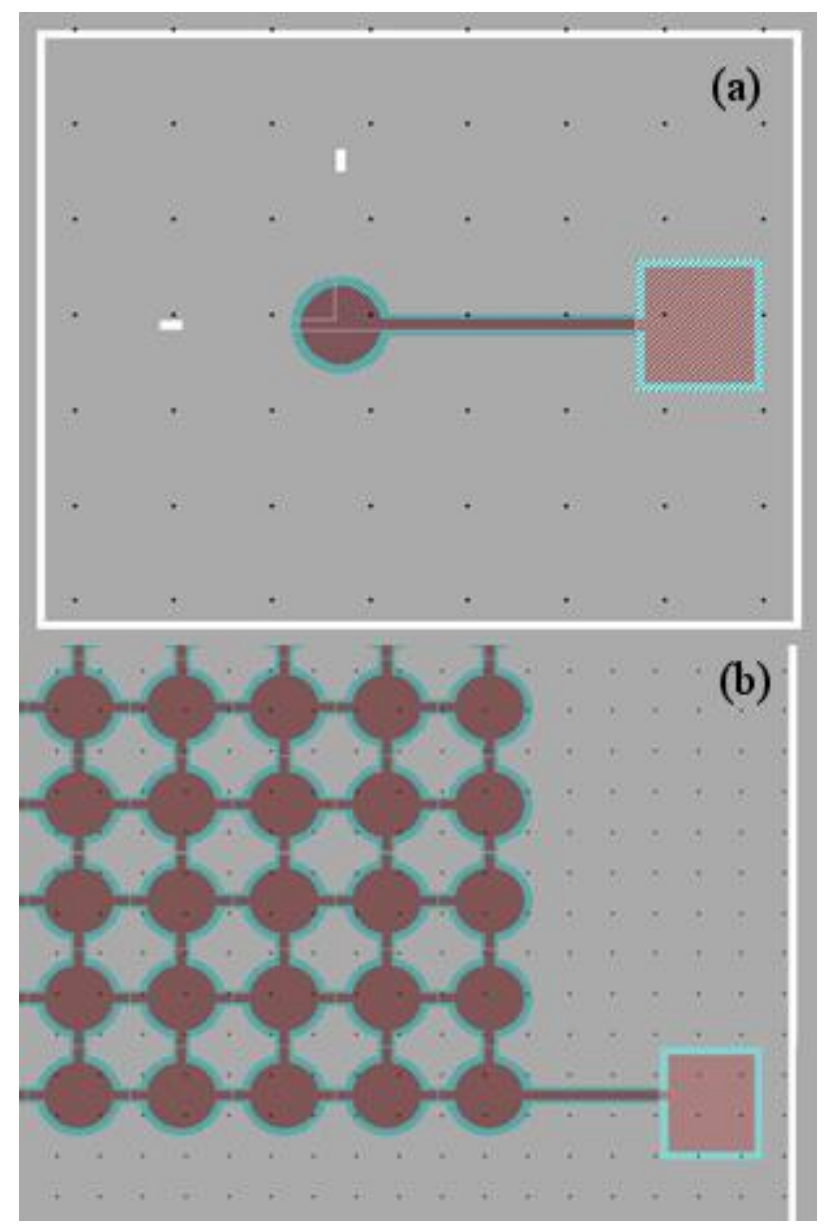

Figure 2. Design of the CMUTs: (a) Unit cell with a $50 \mu \mathrm{m}$ radius membrane, (b) Square lattice of $13 \times 1350 \mu \mathrm{m}$ radius membranes.

\section{3. Fabrication}

The focus of this paper is to develop a repeatable and efficient fabrication process, providing membranes that can be tested mechanically and electrically. Each fabrication step is thoroughly studied and optimized as much as possible in terms of shapes, dimensions, surface flatness, straightness of sidewalls. 


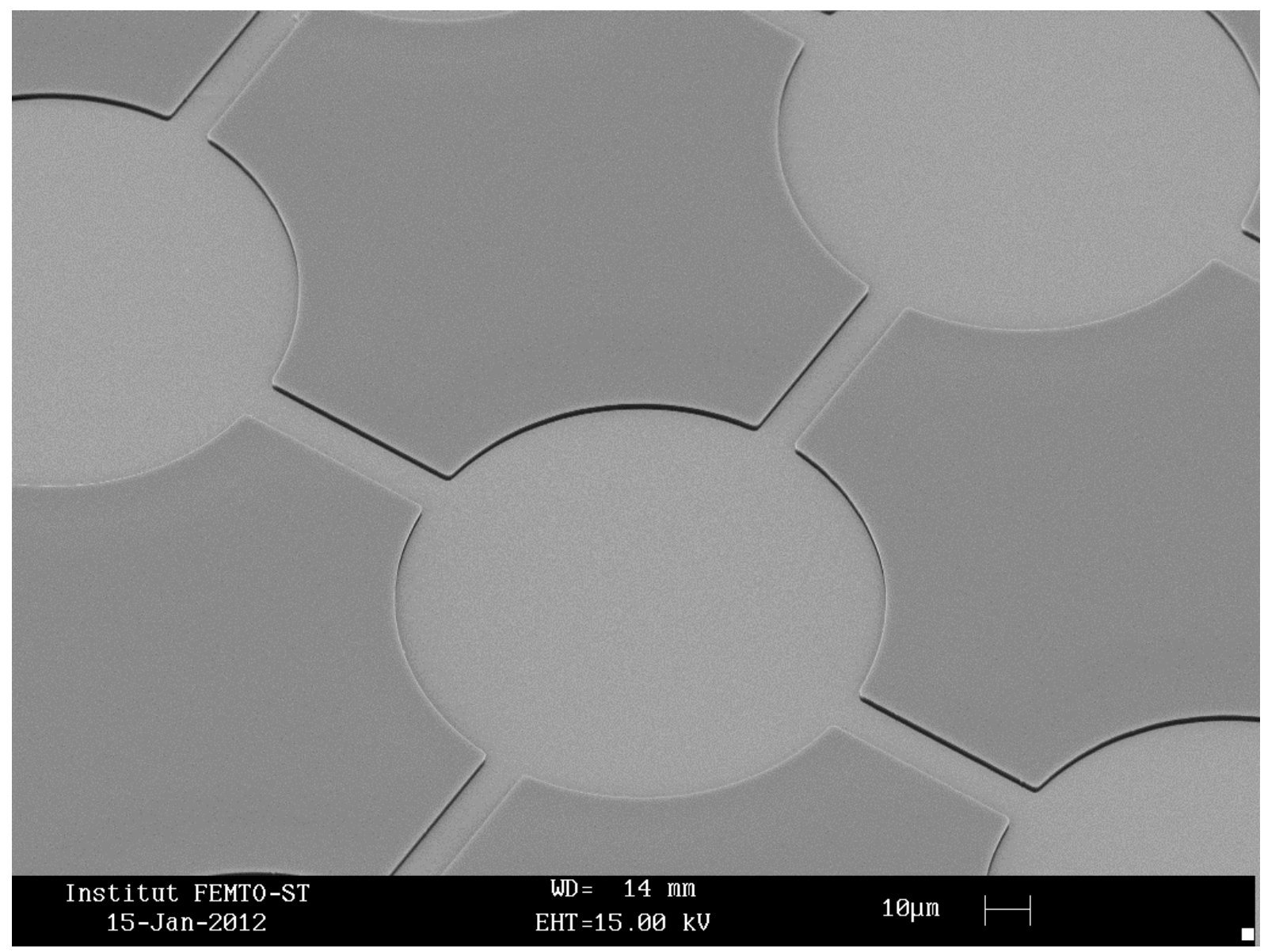

Figure 3. Scanning electron microscope view of the network of cavities on the glass wafer.

For instance, a buffered hydrofluoric acid solution with a ratio of ammonium fluoride solution (NH4F $40 \%$ ) to hydrofluoric acid solution (HF 50\%) equal to 7:1 is used to etch the cavities (figure 3). Since this type of etching is isotropic, the etching ratio is equal in the vertical and the lateral directions. The lateral etching is taken into account in the layout definition of the membranes radii. The etching of the glass with the buffered hydrofluoric acid allows a well-defined curvature of the side wall of the rim of the membrane and a flat bottom of the cavity (figure $4 a$ ). Dry plasma etching with $\mathrm{C}_{4} \mathrm{~F}_{8}$ gas is also used to make the cavities but the resist mask was damaged due to excessive heating, leading to cavities that were curved in the bottom (figure $4 b$ ) and not uniform across the wafer. 


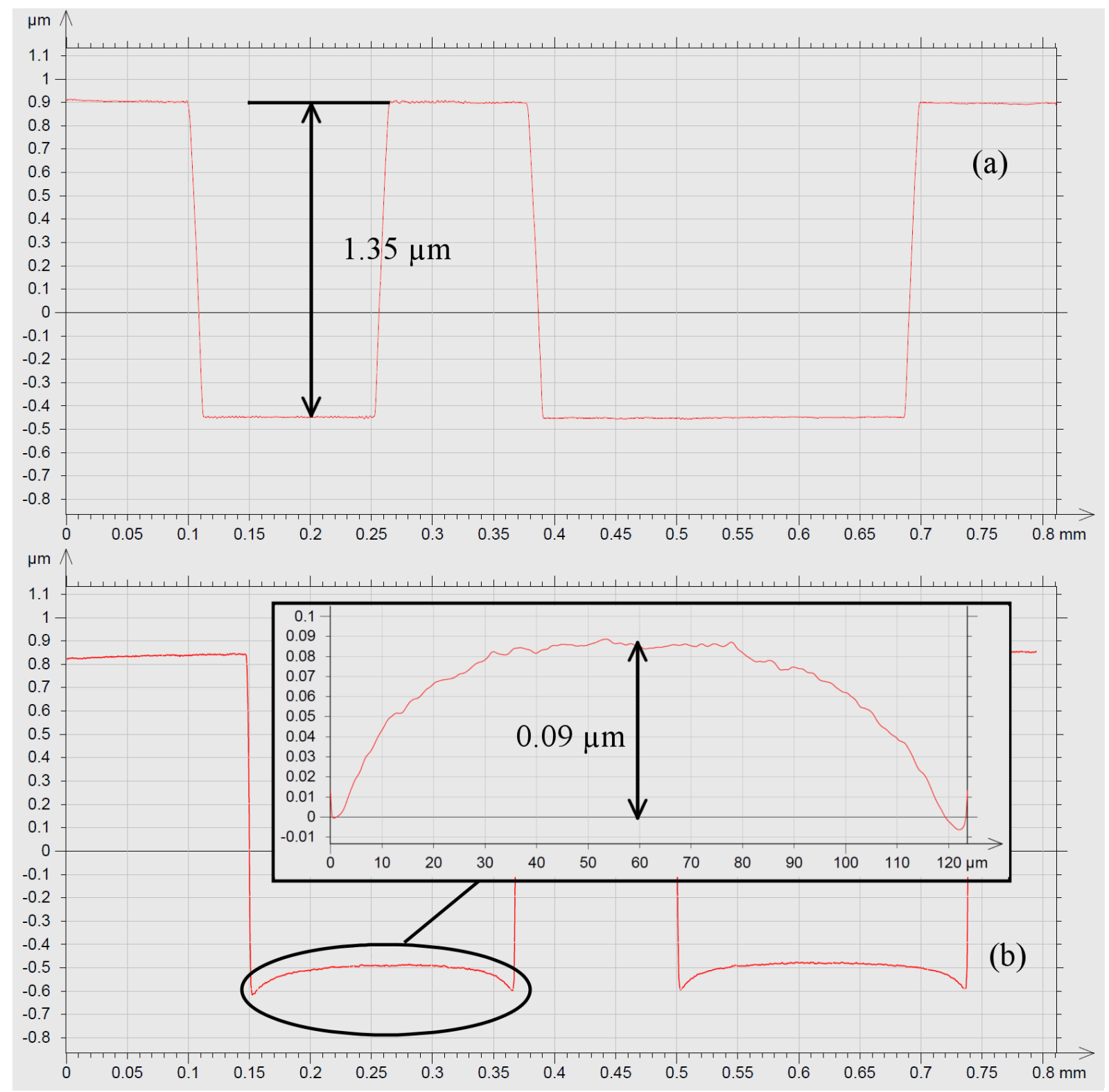

Figure 4. Flatness measurement: (a) flatness measurement after BHF etching, (b) flatness measurement after dry etching.

The fabrication of the bottom electrode with Titanium/Gold deposition through the second lithography

5 step is then performed without any problem (figure 5a and figure $5 \mathrm{~b}$ ). The photoresist used in this step is $3 \mu \mathrm{m}$ thick in order to perfectly coat the sidewalls of the cavities. This ensures that there will be no burrs or smashes on the electrodes, as well as on the $10 \mu \mathrm{m}$ wide connection wire. 


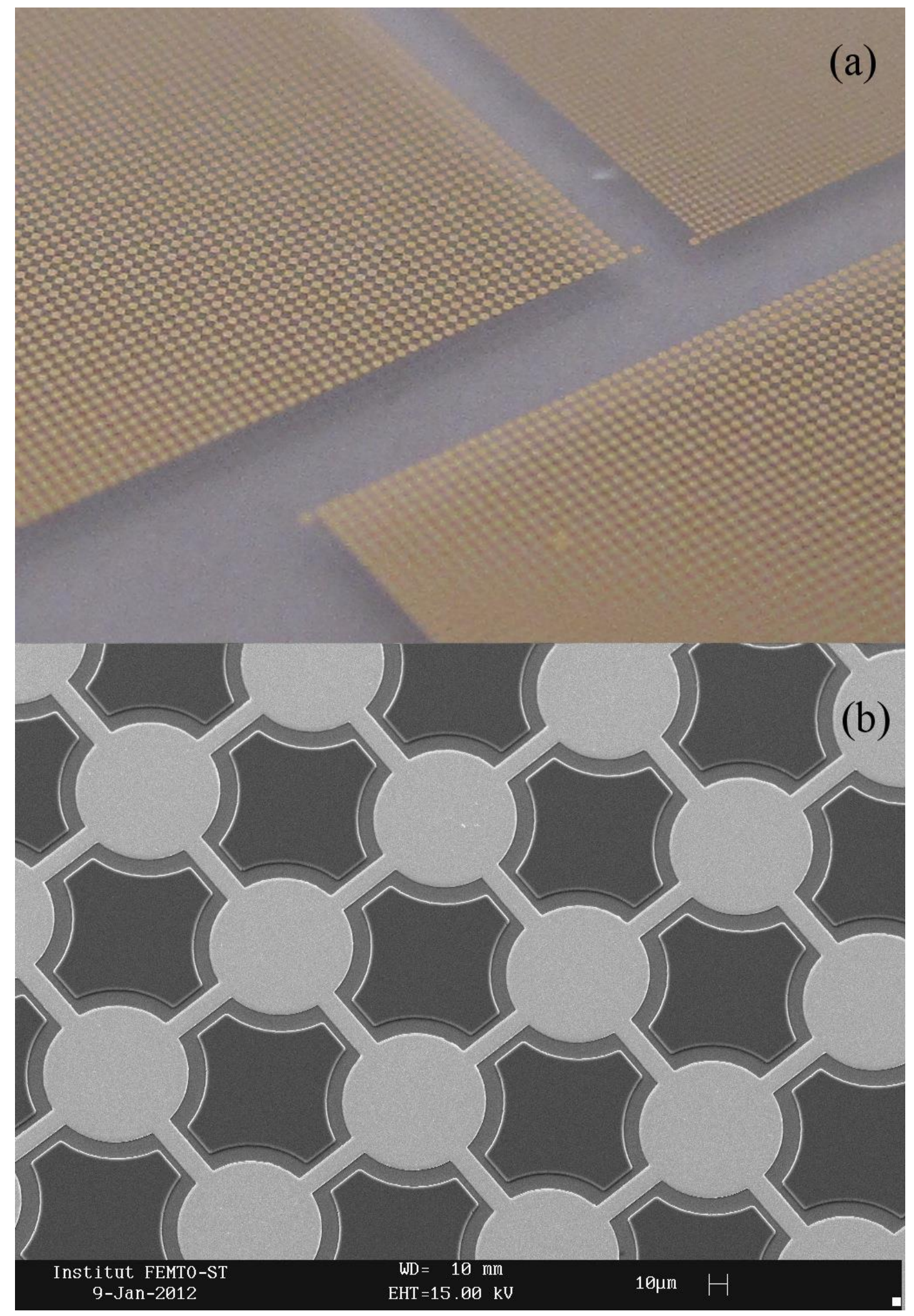

Figure 5. Bottom electrodes in the cavities of the glass wafer: (a) macroscopic picture of the glass wafer with the bottom electrodes, (b) Scanning electron microscope view of the same bottom electrodes. 
The bonding is the most critical step as a SOI wafer is introduced in the process. The SOI wafer is 505 $\mu \mathrm{m}$ (silicon handle layer) $/ 2 \mu \mathrm{m}$ (oxide layer) $/ 1.5 \mu \mathrm{m}$ (silicon device layer) thick and it is bonded on a Pyrex 7740 glass substrate with a thickness of $520 \mu \mathrm{m}$. First, a chromic-sulfuric acid solution (H2SO4, $\left.\left(\mathrm{K}_{2}\right) \mathrm{Cr}_{2} \mathrm{O}_{7}\right)$ is used to clean organic components from SOI and glass wafers during 10 minutes. After rinsing, the SOI and glass wafers are placed in the SUSS Microtec CL200 cleaner for a megasonic cleaning with de-ionized water, a drying and a prebonding by contacting the wafers. These cleaning steps are very important to eliminate void sources, allowing better adhesion during the anodic bonding. The anodic bonding of the SOI wafer to the glass wafer is performed in a vacuum chamber at a temperature of $350{ }^{\circ} \mathrm{C}$ with an EVG501 Bonder. The ramp to the bonding temperature takes 30 minutes. The bonding is performed at low pressure $\left(10^{-3} \mathrm{~Pa}\right)$ with a multistep applied voltage in four periods of 10 minutes: $300 \mathrm{~V}, 500 \mathrm{~V}, 700 \mathrm{~V}$ and lastly $900 \mathrm{~V}$. Gradually ramping the voltage limits the peak current due to the charge carriers in the glass. High current may induce arcing and high electric field may impact on mobile structures. A voltage of $900 \mathrm{~V}$ is the maximum value that can be applied without harming the bottom electrodes. A bonding with a maximum voltage of $1100 \mathrm{~V}$ has been tested and the bottom electrodes were damaged. The $505 \mu \mathrm{m}$ thick silicon substrate stiffens the future $1.5 \mu \mathrm{m}$ thick membranes during bonding and the collapse due to high voltage is thus avoided. Moreover, thanks to the $2 \mu \mathrm{m}$ thick buried oxide in SOI, no damages are observed in accordance with usual breakdown field in the order of $2000 \mathrm{~V} / 2 \mu \mathrm{m}$. A damaged buried oxide could have caused damages in the SOI layer that will constitute the membrane at the end of the process. The buried oxide will thus play its role of wet etch stop during the $\mathrm{KOH}$ etching in the next step. The anodic bonding phase proposed in this paper is quite similar to the method developed by Kim and Blick 2004 and Qiao et al 2010 respectively for integrated bio-electric circuits and deformable mirror applications.

The anodic bonding is followed by the etching of the SOI handle layer and the silicon oxide layer. The etching of the SOI handle layer is performed in a $\mathrm{KOH}$ solution with a concentration of $40 \%$ in mass during 10 hours at $80{ }^{\circ} \mathrm{C}$ (The etch rate is $74 \mu \mathrm{m} / \mathrm{h}$ ). In this step, the buried oxide layer provides an efficient $\mathrm{KOH}$ etch stop. The silicon oxide layer is then removed in a buffered BHF solution. The SOI layer is the BHF etch stop of this step. The bottom electrode pad access is achieved by reactive ion 
etching, using SF3 gas with a pressure of $5.10^{-6}$ bar. The $1.5 \mu \mathrm{m}$ silicon thickness is etched in 15 minutes (figure 6).

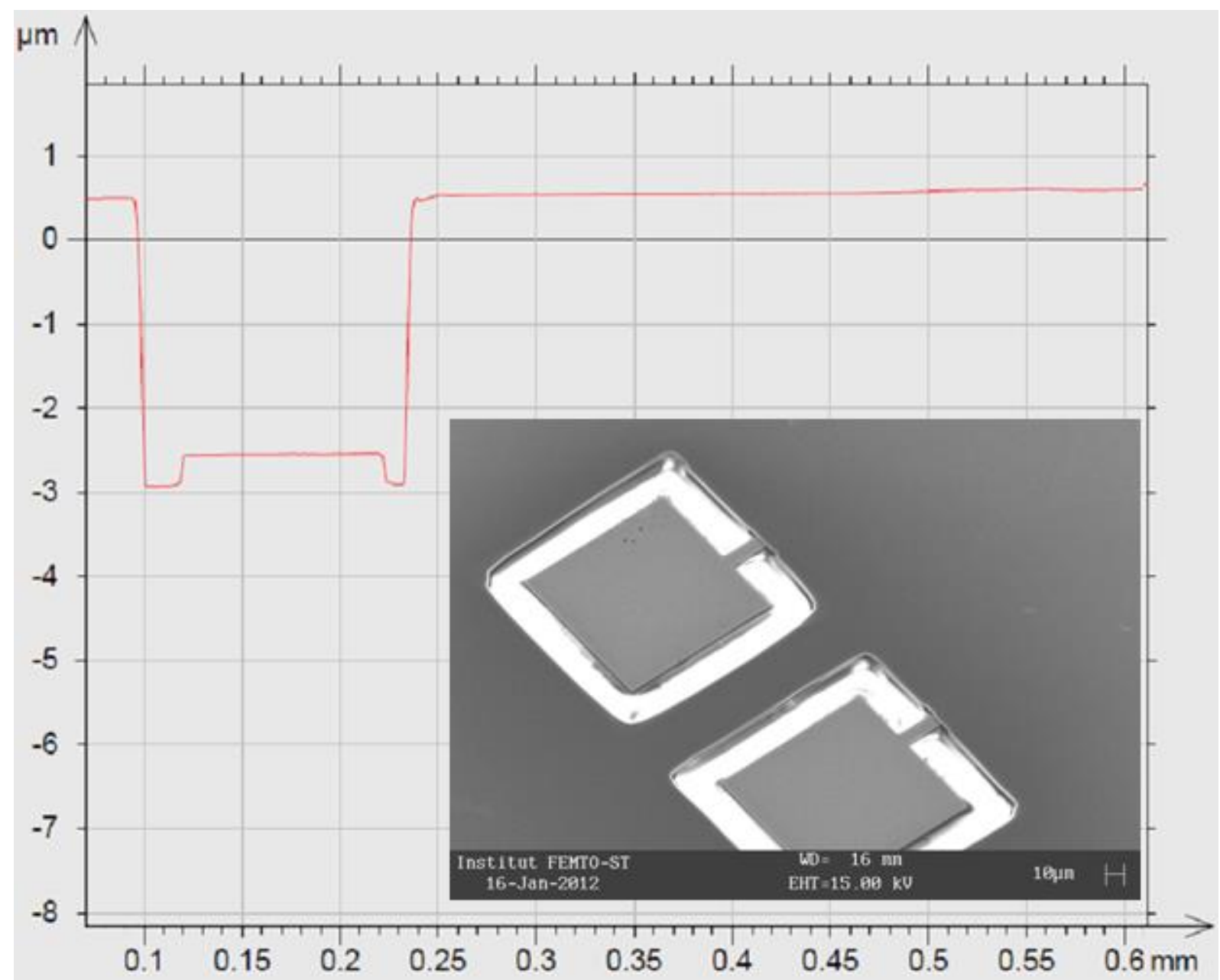

Figure 6. Cross sectional depth profile after the access to the pad is etched.

\section{Electromechanical characterization}

The CMUT characterization is mainly made on unit cells, i.e. on single membranes. The mechanical resonance frequency and the electrical impedance in air are measured. In a first experimental step, the resonance frequency is measured without DC voltage using a POLYTEC laser vibrometer. The vibrometer is composed of a fiber-coupled vibrometer sensor head OFV-534 and an OFV-5000 controller. The controller has a DD300 decoder, being able to measure displacements up to $150 \mathrm{~nm}$ peak to peak at $24 \mathrm{MHz}$ with a resolution of $30 \mathrm{pm} @ 2 \mathrm{Mhz}$. It can be reminded that vibration amplitude is maximized at the mechanical resonance frequencies. TABLE 1 gives the results obtained for the different values of the membrane radius. As expected, the eigenfrequencies decrease as a 
function of the membrane radius. However, some discrepancies, strongly tied to the membrane radius, can be noticed compared to the theoretical values issued from FEM calculations. The next paragraph will propose to relate these discrepancies to residual stress in the membranes possibly induced by the fabrication process of the SOI wafer.

5 In a second experimental step, the evolution of the resonance frequency is measured as a function of the DC voltage to evaluate the well-known electrostatic softening effect. This is made using two ways. The first one uses the POLYTEC laser vibrometer previously described. The DC bias voltage varies from $10 \mathrm{~V}$ to $140 \mathrm{~V}$ with a step of $10 \mathrm{~V}$ for the tested membrane. The AC voltage is set to $0.5 \mathrm{~V}$ peak to peak. The second method uses the impedance curves. The input electrical impedance in air is measured as a function of frequency and for different values of the bias voltage. Measurements are performed using an auto-balanced bridge impedance analyzer (AGILENT HP4294A). The DC bias voltage varies from $50 \mathrm{~V}$ to $170 \mathrm{~V}$, with a step of $10 \mathrm{~V}$, for the tested membrane, having a radius of 50 $\mu \mathrm{m}$. Figure 7 shows the results in accordance with the electrostatic softening effect, i.e. a decreasing of the resonance frequency as a function of the DC voltage. The error bars on the graph for the

15 vibrometer measurement correspond to $\pm 5 \%$. The error made with the impedancemeter is difficult to quantify and is thus not represented on the graph. For clarity reason, the second-order solid curve on figure 7 is the trend fitted to the experimental data points measured using the impedancemeter. 


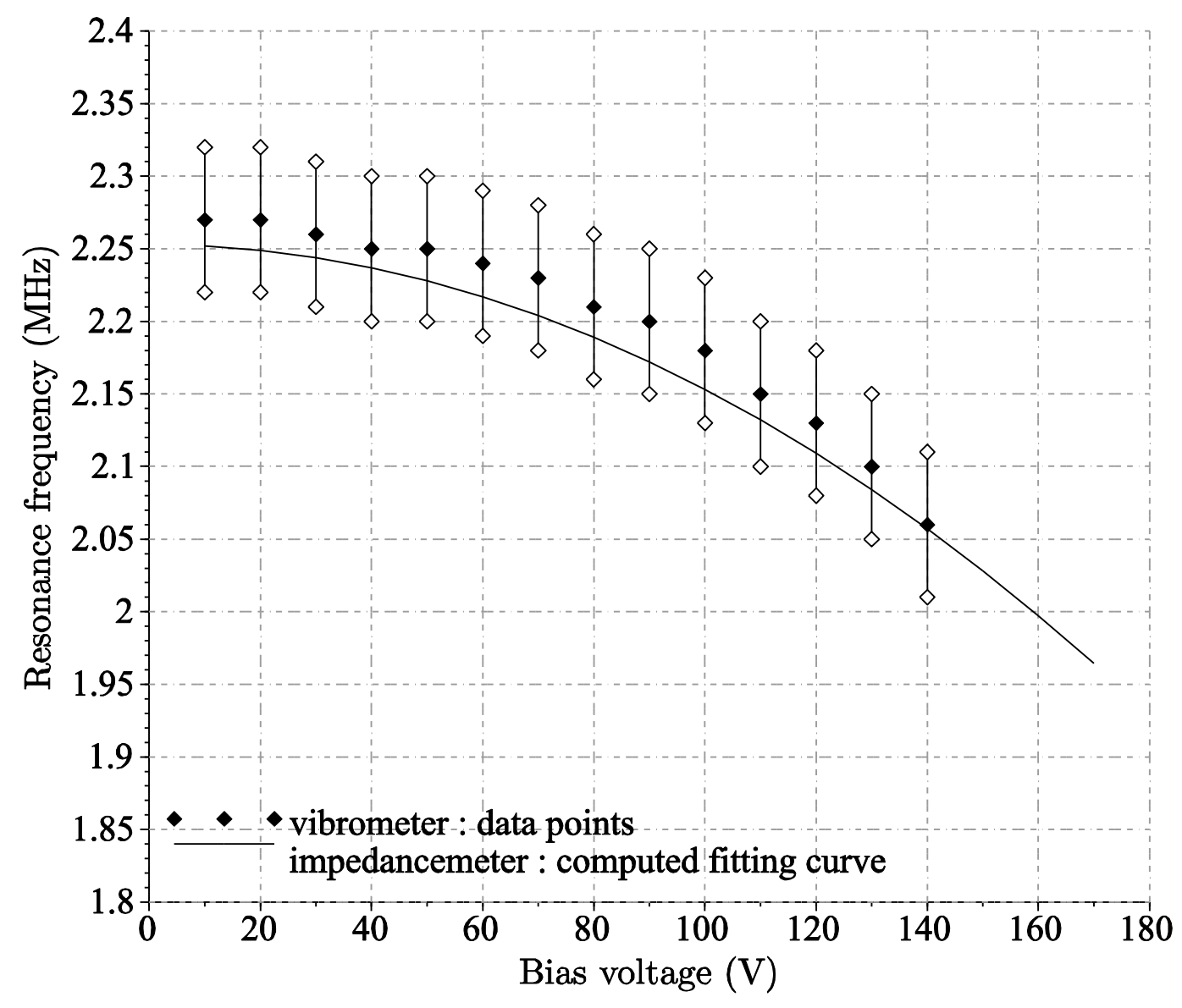

Figure 7. Evolution of the resonance frequency as a function of the DC bias voltage for a $50 \mu \mathrm{m}$ radius and $1.5 \mu \mathrm{m}$ thick membrane. The $\mathrm{AC}$ voltage is set to $0.5 \mathrm{~V}$ peak to peak.

The impedance measurement is also used to determine the electromechanical coupling coefficient. The evolution of the real part of impedance as a function of frequency can be seen in figure 8 for four values of the DC bias voltage, out of thirteen, for clarity reasons. 


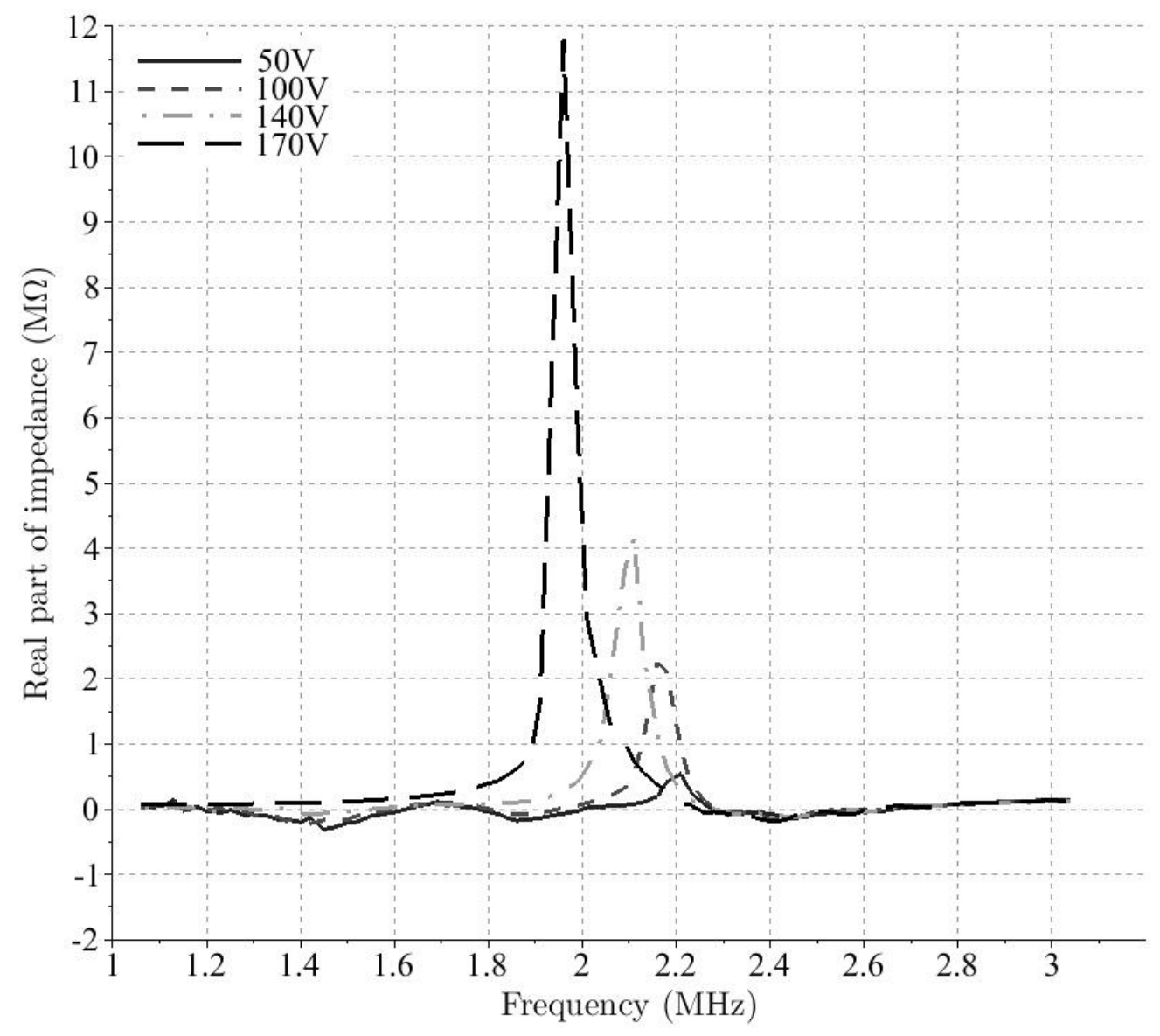

Figure 8. Evolution of the real part of impedance as a function of frequency for different values of the DC bias voltage. The AC voltage is set to $0.5 \mathrm{~V}$ peak to peak.

From these curves, the electrical antiresonance frequencies $\left(f_{R}\right)$ are determined, corresponding to the 5 mechanical resonance frequencies. Figure 9 shows the real part of admittance as a function of frequency for the same values of the bias voltage. 


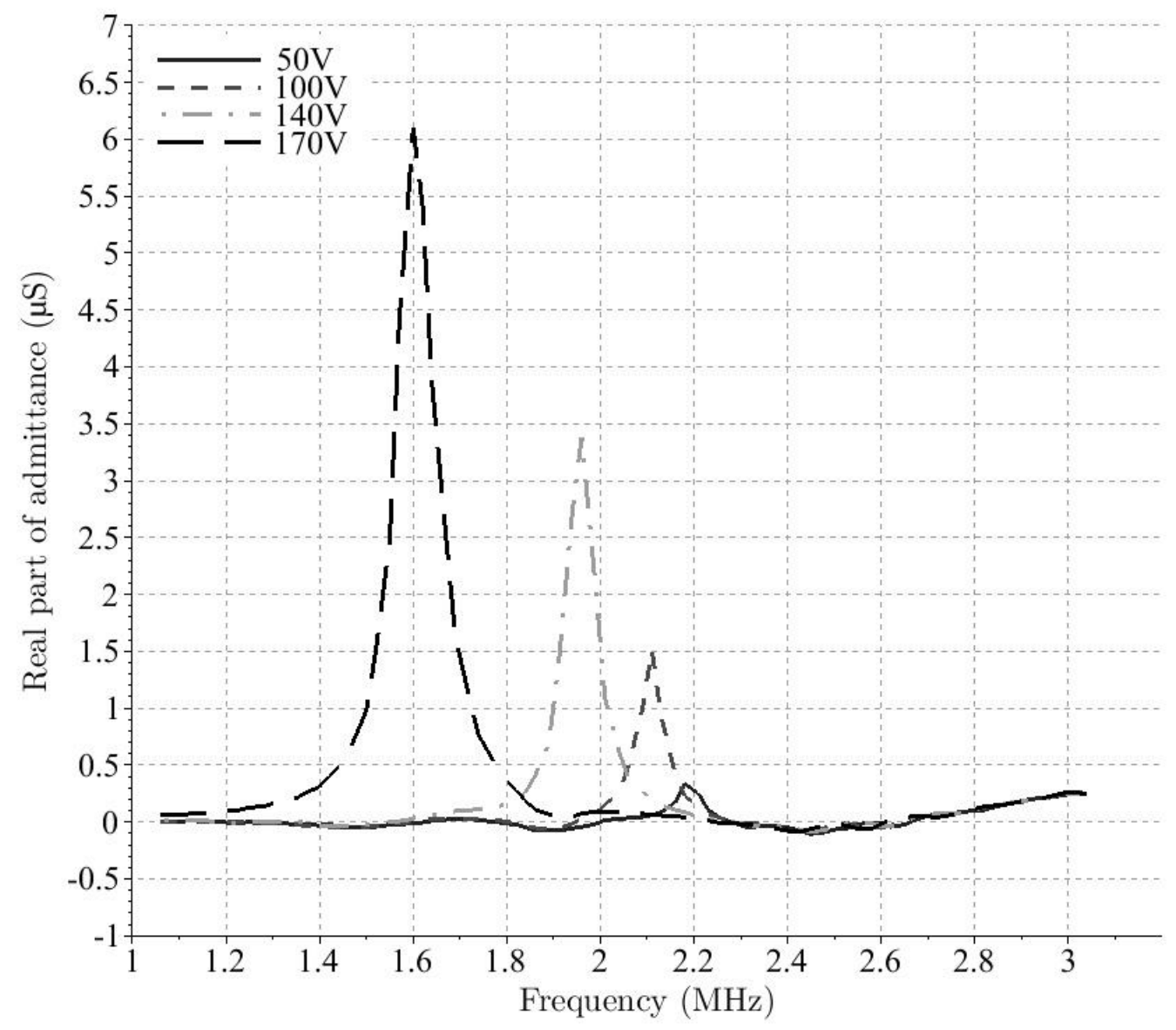

Figure 9. Evolution of the real part of admittance as a function of frequency for different values of the $\mathrm{DC}$ bias voltage. The AC voltage is set to $0.5 \mathrm{~V}$ peak to peak.

The electrical resonance frequencies $\left(f_{Y}\right)$ can be calculated from these curves. The electromechanical coupling coefficient is then defined by the following relation Hunt 1954, Yaralioglu et al 2003:

$$
k_{T}^{2}=1-\left(\frac{f_{Y}}{f_{R}}\right)^{2}
$$

The evolution of the electromechanical coupling coefficient, shown on figure 10, is increasing with the DC voltage. The discretization of the values of $k_{T}^{2}$ comes from the precision of the $f_{Y}$ and $f_{R}$ measurements, especially for the low values of the DC voltage. 


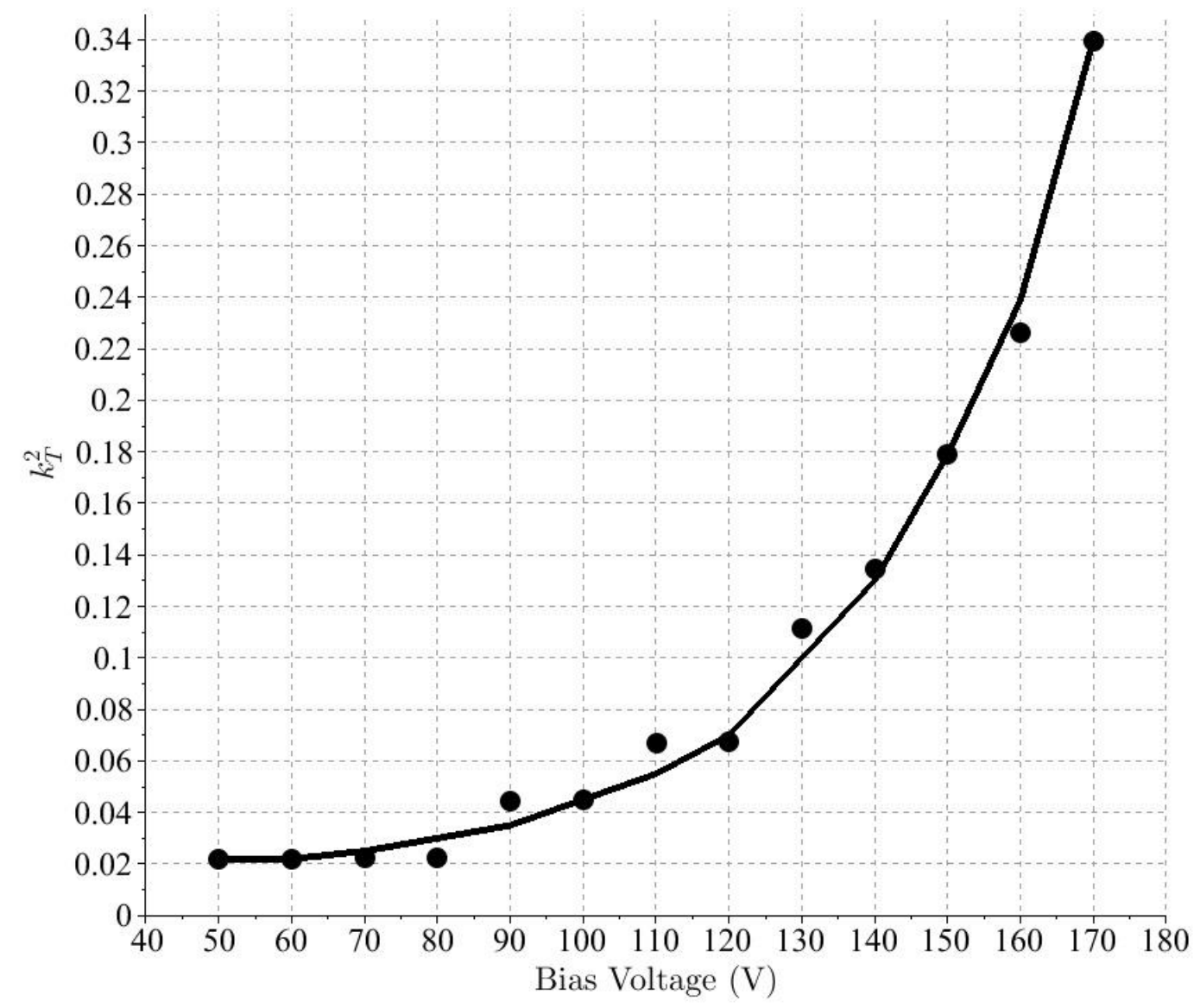

Figure 10. Evolution of the coupling factor as a function of frequency for different values of the DC bias voltage.

For a DC voltage of $170 \mathrm{~V}$, corresponding to $90 \%$ of the theoretical collapse voltage (185 V) for a 50 $\mu \mathrm{m}$ radius membrane, this coefficient is about $58 \%$ (i.e., $34 \%$ for the square of the coupling coefficient). This value is in the same order of what is usually found in the literature (30\% for the square in Teston et al 2006 and in Yaralioglu et al 2003) for structures that exhibit similar significant parasitic capacitances. The parasitic capacitances will be reduced in the process described here for example by patterning the top electrode properly and thus avoiding the parasitic capacitance due to the wire connecting the pad to the bottom electrode. 


\section{Residual stress in the silicon membranes}

As shown on table 1, there is a significant difference between the experimental frequencies and the eigenfrequencies computed using ANSYS FEM simulations. This difference gets bigger as the radius of the membrane increases. The sign of the error also changes, being negative for the $50 \mu \mathrm{m}$ radius membrane and then positive for other values of the radius. The experimental frequencies are measured with a $10 \mathrm{~V}$ DC bias voltage and a $0.5 \mathrm{~V}$ peak to peak AC voltage, leading to maximal deflections less than $2.5 \mathrm{~nm}$ peak to peak for the $150 \mu \mathrm{m}$ radius membranes. This ensures that the discrepancies are not due to stress stiffening, since the deflection to thickness ratio is much less than $10 \%$.

Table 1. Eigenfrequencies for different membrane radius

\begin{tabular}{cccc}
\hline $\begin{array}{c}\text { Radius of the membrane } \\
(\mu \mathrm{m})\end{array}$ & $\begin{array}{c}\text { Experimental } \\
\text { eigenfrequency }(\mathrm{MHz})\end{array}$ & $\begin{array}{c}\text { Theoretical eigenfrequency } \\
(\mathrm{MHz})^{\mathrm{a}}\end{array}$ & $\begin{array}{c}\text { Error }(\%) \\
50 \\
70\end{array}$ \\
\hline 1.26 & 2.30 & +6 \\
100 & 0.82 & 1.17 & +29 \\
150 & 0.6 & 0.58 & +57 \\
\hline
\end{tabular}

10

${ }^{a}$ : calculated with ANSYS ${ }^{\circledR}$, taking into account the anisotropy of silicon

These results suggest that the hypotheses used in the theoretical approach are not correct. The simulation indeed assumes that the internal stress was zero and that the rim of the membrane was perfectly clamped (no displacement and no rotation at the rim of the membrane).

15 The idea is to determine numerically the value of the residual stress so that the numerical value of the first eigenfrequency corresponds to the experimental one, for each value of the radius membrane. Two types of boundary conditions are tested. In a first calculation, all the degrees of freedom at the clamped rim of the membrane are restrained. In a second calculation, the rotations are released. Moreover, the stress is supposed to be homogeneous in the membrane: tensile state or compressive state. It is assumed here that the residual stress is a thin film material parameter, independent of the plate radius. Table 2 shows that the clamped rim model does not support this assumption and thus will 
not be considered a suitable model hereafter. This is also confirmed by the change of sign of the residual stress, being compressive for the $50 \mu \mathrm{m}$ radius and then becoming tensile for the other values of the radius. In contrast, the mean value calculated when the rotations are released exhibits less deviation. This assumption has been already taken into account in previous works (Fang and Wicket 5 1996, Paul and Baltes 1999). For instance, Fang observes in the case of a cantilever bonded on a substrate that the nominally-clamped end of the free part of the cantilever undergoes a slight rotation due to an in-plane deformation of the bonded part from the residual stress field.

Table 2. Residual stress calculated for two different boundary conditions: clamped rim and rotations released.

\begin{tabular}{ccc}
\hline Radius of the membrane $(\mu \mathrm{m})$ & $\begin{array}{c}\text { Residual stress for a clamped } \\
\text { rim (MPa) }\end{array}$ & $\begin{array}{c}\text { Residual stress with rotations } \\
\text { released (MPa) }\end{array}$ \\
\hline 50 & -5 & 159 \\
10 & 13 & 95 \\
150 & 46 & 124 \\
\hline Mean value & 93 & 120 \\
Standard deviation & 37 & 25 \\
\hline
\end{tabular}

To go further, the evolution of the resonance frequency as a function of the residual stress is investigated, with both configurations of boundary conditions, with all the degrees of freedom restrained (diamond points in figure 11) and with the rotations released (circle points in figure 11).

15 The diamond points are always above the circle points because, for a given geometry, a clamped diaphragm has a higher resonant frequency than a simply supported one. On the same plot, the experimental resonance frequency is drawn with a dashed line and an area corresponding to the values of $\pm 10 \%$ around the experimental resonance frequency is plotted (gray area). This percentage 
approximately corresponds to the measurement scatterings of the experimental eigenfrequency over about ten cells for each radius. The curves for the different values of the membrane radius are shown on figure 11.
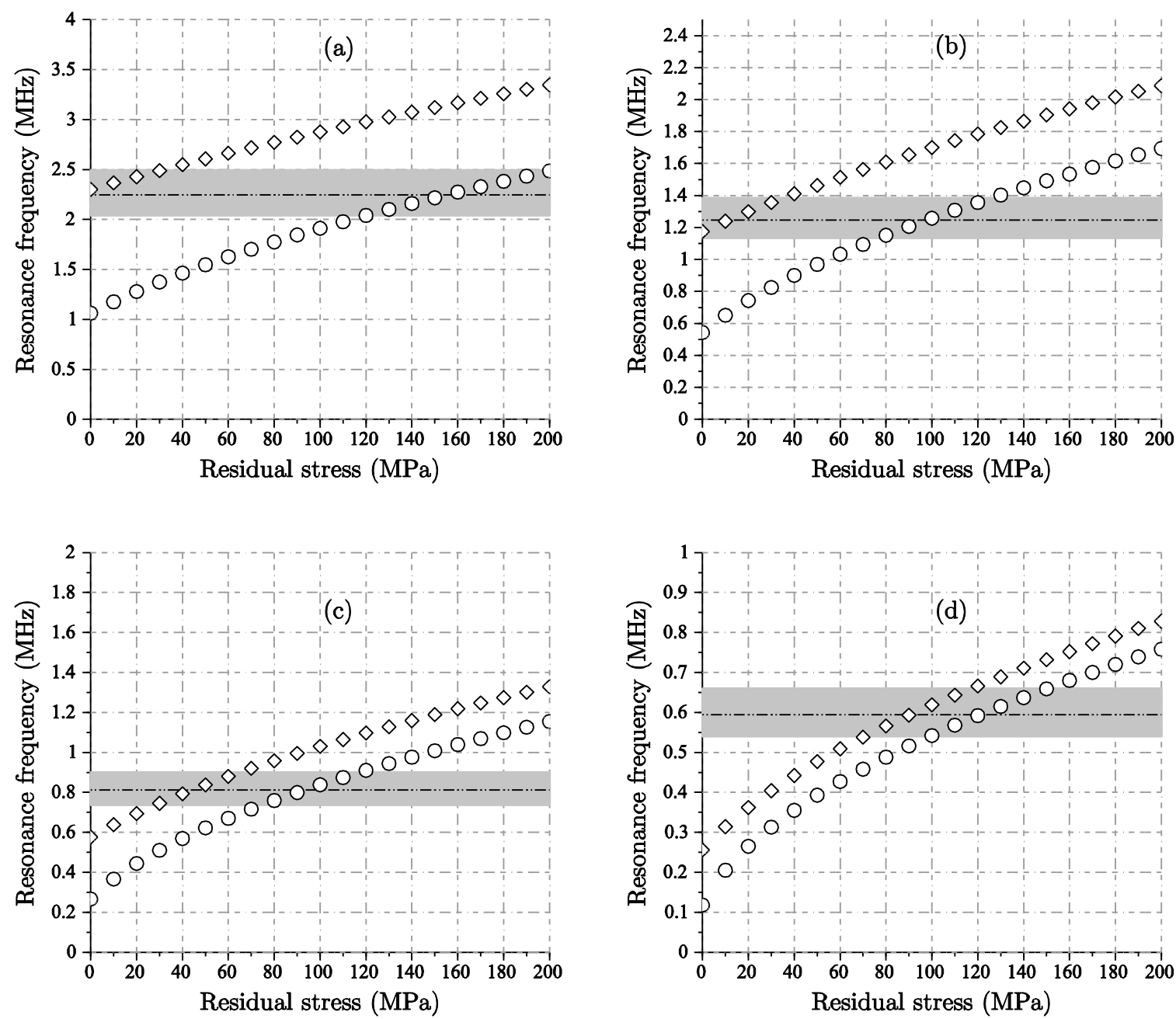

5 Figure 11. Evolution of the resonance frequency as a function of the residual stress, with two configurations of boundary conditions, with all the degrees of freedom restrained (diamond points) and with the rotations released (circle points) for different values of the membrane radius: $50 \mu \mathrm{m}$ (a), $70 \mu \mathrm{m}(\mathrm{b}), 100 \mu \mathrm{m}$ (c) and $150 \mu \mathrm{m}$ (d). The dashed line represents the experimental resonance frequency and the gray area corresponds to the values of $\pm 10 \%$ around the experimental resonance frequency.

Using these curves, the lowest upper value of the residual stress and the highest lower value of the residual stress are found. To do so, it is assumed that the effective boundary conditions must lie between the first case (all degrees of freedom restrained) and the second case (rotations released). In 
this condition, the lowest upper value of the residual stress is found for each curve when the circle points is above the $+10 \%$ limit, corresponding to the top line of the gray area. The highest lower value of the residual stress is found when the diamond points are under the $-10 \%$ limit, corresponding to the bottom line of the gray area. For instance, for the radius $150 \mu \mathrm{m}$, the lowest upper value of the residual stress is found to be $150 \mathrm{MPa}$. Another example is the highest lower value of the residual stress for the radius $100 \mu \mathrm{m}$, found to be $30 \mathrm{MPa}$. Assuming that the residual stress has to be independent of the radius of the membrane, this residual stress has to be included in the boundaries $70 \mathrm{MPa}-120 \mathrm{MPa}$.

Of course, the actual boundary conditions must fall between the first case, totally clamped, and the second case, rotations released. The actual boundary conditions are a consequence of the fabrication process of the membranes since the thickness of the SOI is the same in the bonded area than in the area suspended over the cavity. To go one step further in this investigation, a torsional stiffness is added to the nodes of the membrane rim, in the numerical model. Then, for each value of the residual stress within the range $70 \mathrm{MPa}-120 \mathrm{MPa}$ in steps of $10 \mathrm{MPa}$, the first eigenfrequency is computed for different values of the torsional stiffness within the range $10^{-9} \mathrm{~N} \cdot \mathrm{m} / \mathrm{rad}$ and $10^{-4} \mathrm{~N} . \mathrm{m} / \mathrm{rad}$. The range of the torsional stiffness is chosen in such a way that the computation will lead to a numerical eigenfrequency falling within the order of magnitude of the experimental one. The value of the residual stress is said to be possible if a value of the torsional stiffness leading to a numerical eigenfrequency falling within the range $\pm 10 \%$ around the experimental one can be found, for the four values of the membrane radii. Using this method, it can be seen in figure 12 that for the value of the residual stress $70 \mathrm{MPa}$, it is not possible to find a value of the torsional stiffness leading to a convenient numerical eigenfrequency. 


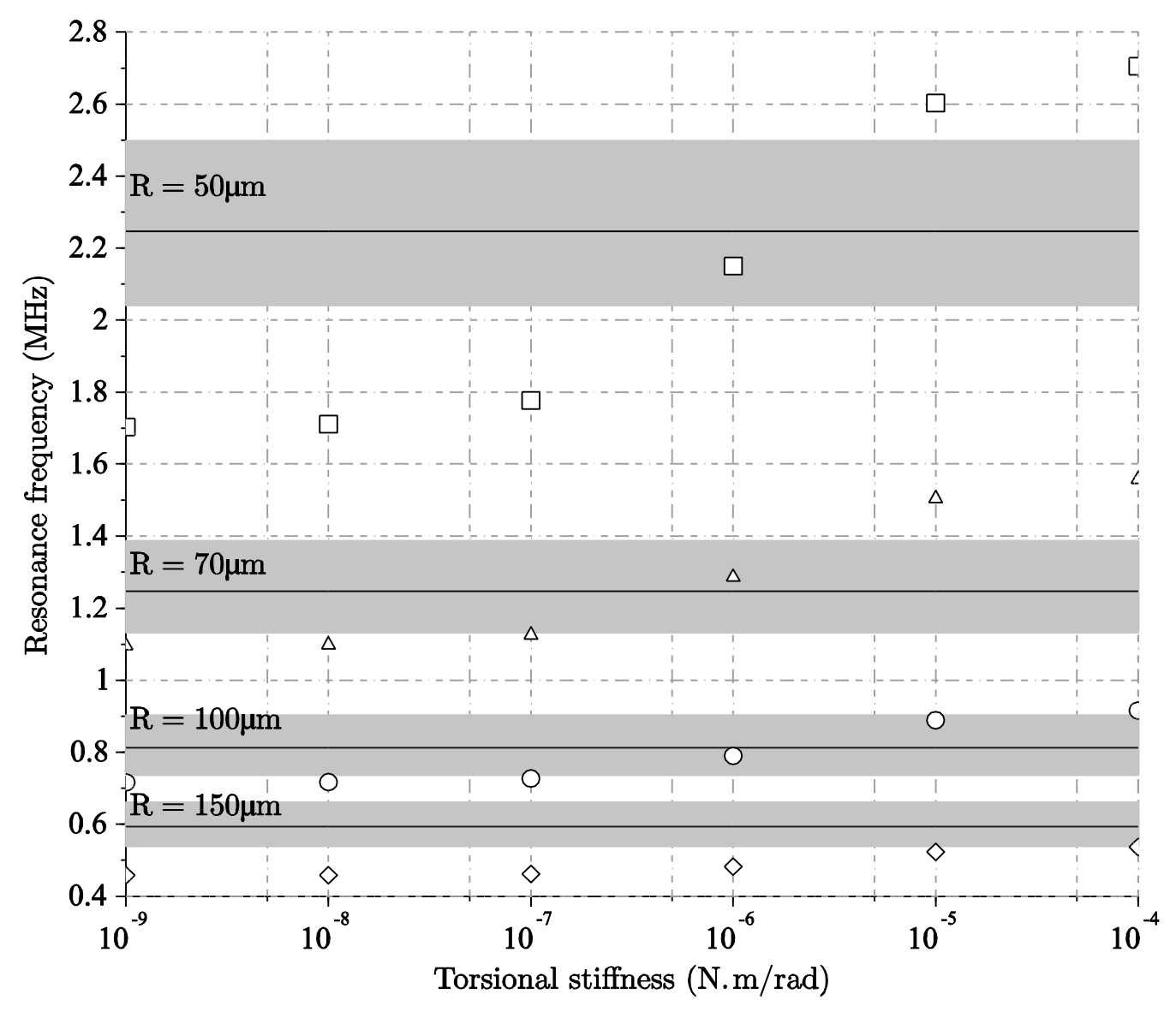

Figure 12. For a residual stress of $70 \mathrm{MPa}$, evolution of the resonance frequency as a function of the torsional stiffness for different values of the membrane radius: $50 \mu \mathrm{m}$ (squares), $70 \mu \mathrm{m}$ (triangles), 100 $\mu \mathrm{m}$ (circles) and $150 \mu \mathrm{m}$ (diamonds). The lines represent the experimental resonance frequencies for 5 the different membrane radii and the gray area corresponds to the values of $\pm 10 \%$ around the experimental resonance frequencies.

On the other hand, for the residual stress of $100 \mathrm{MPa}$, figure 13 indicates that a value of the torsional stiffness between $2.10^{-7} \mathrm{~N} \cdot \mathrm{m} / \mathrm{rad}$ and $1.10^{-6} \mathrm{~N} \cdot \mathrm{m} / \mathrm{rad}$ gives a value of the numerical eigenfrequency that is in the range of the experimental one for all the values of the membrane radius. 


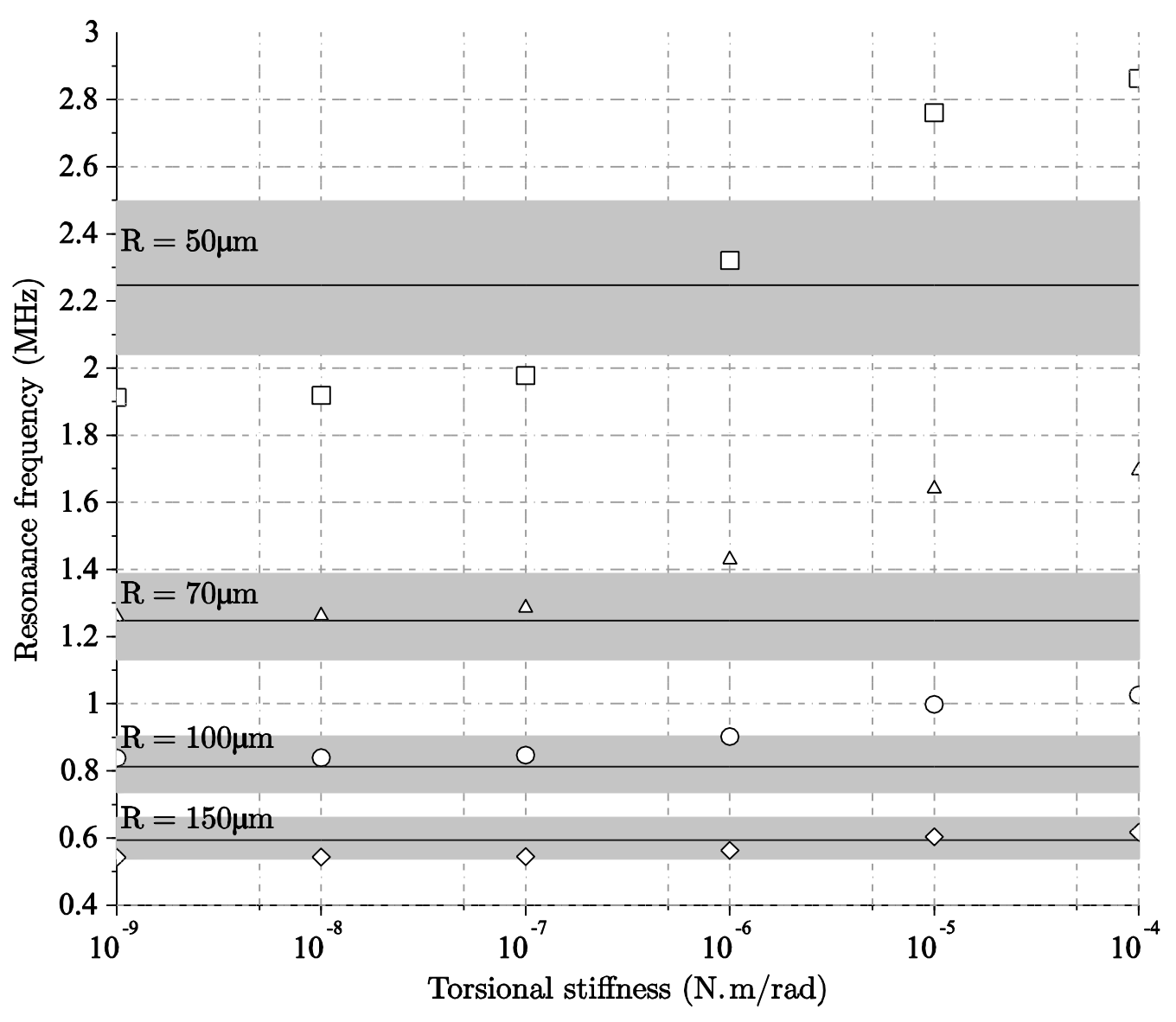

Figure 13. For a residual stress of $100 \mathrm{MPa}$, evolution of the resonance frequency as a function of the torsional stiffness for different values of the membrane radius: $50 \mu \mathrm{m}$ (squares), $70 \mu \mathrm{m}$ (triangles), 100 $\mu \mathrm{m}$ (circles) and $150 \mu \mathrm{m}$ (diamonds). The lines represent the experimental resonance frequencies for 5 the different membrane radii and the gray area corresponds to the values of $\pm 10 \%$ around the experimental resonance frequencies.

At the end of the calculations, the possible values of the residual stress are in the range $90 \mathrm{MPa}-110$ MPa for a torsional stiffness around $2.10^{-7} \mathrm{~N} . \mathrm{m} / \mathrm{rad}$. For an unloaded circular plate, the bending moment along the circumference is related to the rim rotation by the formula:

$$
M=K \theta
$$

Where $K$ can be expressed by:

$$
K=\frac{\pi \cdot E \cdot h^{3}}{6 \cdot(1-v)}
$$


Where $E$ is the Young's modulus of the membrane, $150 \mathrm{GPa}, h$ the thickness, $1.5 \mu \mathrm{m}, v$ the Poisson's ratio, 0.22 . Using equation 3 , a value of $3 \cdot 4 \cdot 10^{-7} \mathrm{~N} \cdot \mathrm{m} / \mathrm{rad}$ is found for the equivalent torsional stiffness $\mathrm{K}$, which is close to $2 \cdot 10^{-7} \mathrm{~N} \cdot \mathrm{m} / \mathrm{rad}$.

\section{Conclusion}

In this paper, the anodic bonding of an SOI wafer and a glass wafer is now proved to be a relevant alternative fabrication method for CMUTs. This method takes advantage of usual benefits of Si-wafer bonding, i.e. uniform membrane thicknesses and well-controlled mechanical properties of single crystal silicon. Moreover, the glass wafer involves no additional parasitic capacitances, transparency capability aiding wafers alignment if needed and lower bonding temperatures suitable with CMOS circuits.

Unit cells and square lattices of $13 \times 13$ cells are fabricated in accordance with preliminary design. On the one hand, the cavities have a well-defined radius and a depth and flatness controlled by the etching time during the BHF etching. On the other hand, the geometry of vibrating membranes is determined by the thickness of the SOI device layer and the radii of the cavities.

The very first results of electromechanical characterization lead to a quite good electromechanical coupling coefficient around $55 \%$ for a DC voltage representing $90 \%$ of the theoretical collapse voltage. However, the experimental eigenfrequencies do not confirm the theoretical calculation, which means that fabricated membranes cannot be considered as clamped free-stressed circular plates. The vibrating membranes are thus prestressed and the actual boundary condition of the membranes is between the clamped and the simply supported membrane. This state can be modeled by a torsional stiffness of $2.10^{-7} \mathrm{~N} \cdot \mathrm{m} / \mathrm{rad}$.

Further developments aim at identifying the origin of the residual stress in the membranes and providing efficient clamping conditions. Concerning the origin of the residual stress, at least two directions of research can be investigated: the amount of stress in the SOI layer generated during the fabrication process of the SOI wafer itself, and the amount of stress in the membranes induced by our fabrication process, especially during the anodic bonding step. If the origin of the residual stress can be identified, a solution might be found to reduce it. Concerning the clamping conditions, membranes 
having a step at the rim of the membrane have to be fabricated. This step will reduce the rotations so that the boundary conditions will be actually clamped at the rim of the membrane. However, these improvements require additional mask levels, leading to a more complicated fabrication process and consequently to a higher probability of failure.

5

\section{Acknowledgements}

This work has been performed in cooperation with the Labex ACTION program (contract ANR-11-LABX-01-01). 
Cianci E, Visigalli L, Foglietti V, Caliano G, and Pappalardo M 2003 Improvements towards a reliable fabrication process for cMUT Microelectronic Engineering 67-68 602-8

5 Ergun A, Huang Y, Zhuang X, Oralkan Ö, Yaralioglu G G and Khuri-Yakub B T 2005 Capacitive micromachined ultrasonic transducers: Fabrication technology IEEE Transactions on Ultrasonics, Ferroelectrics and Frequency Control 52-12 2242-58

Fang W, Wicket J A 1996 Determining mean and gradient residual stresses in thin films using micromachined cantilevers Journal of Micromechanics and Microengineering 6 301-9

Haller M and Khuri-Yakub B T 1994 A surface micromachined electrostatic ultrasonic air transducer IEEE Ultrasonics Symposium Cannes 1-4 Nov. 19942 1241-44 micromachined ultrasonic transducers (CMUTs) with isolation posts Ultrasonics 48 74-81

Hunt F V 1954 The analysis of transduction, and its historical background Cambridge Electroacoustics MA Harvard Univ. Press

Kim H and Blick R 2004 Bonding silicon-on-insulator to glass wafers for integrated bio-electronic circuits Applied Physics Letters 85-12 2370-72

Knight J, McLean J and Degertekin F 2004 Low Temperature Fabrication of Immersion Capacitive 25 Micromachined Ultrasonic Transducers on Silicon and Dielectric Substrates IEEE Transactions on Ultrasonics, Ferroelectrics and Frequency Control 51-10 1324-33 
Khuri-Yakub B T, Oralkan Ö 2011 Capacitive micromachined ultrasonic transducers for medical imaging and therapy Journal of Micromechanics and Microengineering 21 1-11

Ladabaum I, Jin X, Soh H, Atalar A and Khuri-Yakub B T 1998 Surface Micromachined Capacitive

Ultrasonic Transducers IEEE Transactions on Ultrasonics, Ferroelectrics and Frequency Control 45$3678-90$

Liu J, Oakley C and Shandas R 2009 Capacitive micromachined ultrasonic transducers using commercial multi-user MUMPs process: Capability and limitations Ultrasonics 49 765-73

10

Manzanares A and Espinosa F 2012 Air-coupled MUMPs capacitive micromachined ultrasonic transducers with resonant cavities Ultrasonics $\mathbf{5 2} 482-89$

Paul O and Baltes H 1999 Mechanical behavior and sound generation efficiency of prestressed, elastically clamped and thermomechanically driven thin film sandwiches Journal of Micromechanics and Microengineering 9 19-29

Qiao D, Wang S and Yuan W 2010 A continuous-membrane micro deformable mirror based on anodic bonding of SOI to glass wafer Microsystems Technology 16 1765-69

Salim M S, AbdMalek M F, Heng R B W, Juni K M and Sabri N 2012 Capacitive Micromachined Ultrasonic Transducers: Technology and Application Journal of Medical Ultrasound 20 8-31

Teston F, Meynier C, Jeanne E, Felix N and Certon D 2006 Characterization standard of CMUT device based on electrical impedance measurements IEEE Ultrasonics Symposium Vancouver 2-6 Oct. $20061963-66$ 
Tsuji Y, Kupnik M and Khuri-Yakub B T 2010 Low temperature process for CMUT fabrication with wafer bonding technique IEEE Ultrasonics Symposium San Diego CA 11-14 Oct. 2010 551-54

Wygant I O, Kupnik M, Windsor J C, Wright W M, Wochner M S, Yaralioglu G G, Hamilton M F 5 and Khuri-Yakub B T 200950 kHz Capacitive Micromachined Ultrasonic Transducers for Generation of Highly Directional Sound with Parametric Arrays IEEE Transactions on Ultrasonics, Ferroelectrics, and Frequency Control 56-1 193-202

Yamaner F Y, Olcum S, Bozkurt A, Koymen H and Atalar A 2011 Design and implementation of 10 capacitive micromachined ultrasonic transducers for high power IEEE Ultrasonics Symposium, Istanbul, 18-21 Oct. 2011 1012-1015

Yamaner F Y, Olçum S, Oğuz H K, Bozkurt A, Köymen H and Atalar A 2012 High-power CMUTs: design and experimental verification IEEE Transactions on Ultrasonics, Ferroelectrics, and Frequency Control 59-6 1276-84

Yaralioglu G G, Ergun A S, Bayram B, Haeggström E and Khuri-Yakub B T 2003 Calculation and Measurement of Electromechanical Coupling Coefficient of Capacitive Micromachined Ultrasonic Transducers IEEE Transactions on Ultrasonics, Ferroelectrics, and Frequency Control 50-04 449-56 
First Author: Mohamed Lamine Fayçal BELLAREDJ holds an engineering degree in electronics (2005) and a magister degree in physics (2007) from the University of Sciences and technologies of Oran USTO, Algeria. He completed a PhD degree in micromechanics at the University of FrancheComté in Besançon France in 2013. His research interests include third generation solar cells, microelectromechanical systems (MEMS) and capacitive micromachined ultrasonic transducers (CMUTs).

Second Author: Gilles BOURBON was born in Héricourt, France, in 1967. He received the Ph.D. degrees in Mechanics from the University of BESANCON, France, in 1994. He worked as a PostDoctoral Researcher at LIMMS (C.N.R.S. / University of Tokyo) in 1997-1998. He worked as an Engineer Researcher at SilMach SAS (MEMS Product \& Service Company / France) in 2003 - 2009. He is currently an Engineer Researcher at FEMTO-ST. (C.N.R.S. /Besançon,France). His research interests include MEMS, Bulk and Surface micromachining and electrostatic micro actuators.

Third Author: Vincent WALTER graduated from the Mechanics and Microtechnics Engineering School (ENSMM) of Besançon, France, in materials sciences in 1995. He received his Ph.D. degree in May 2001 from the Applied Mechanics Department of the Femto-ST Institute, France. He has been an associate professor at the University of Franche-Comte since 2002, with a delegation period as a research engineer from 2003 to 2009 in SilMach SA (MEMS Product \& Service Company / France). His research is focused on MEMS, with a strong emphasis on electrostatic microactuators.

Fourth Author: Patrice LE MOAL received the Ph.D. degree in mechanical engineering from Université de Franche-Comté in 1993. Since 1994, he works as a Research fellow at the Applied 25 Mechanics Department of FEMTO-ST Institute in Besançon. Between 2003 and 2009, he took part to the creation and the development of SilMach SA (MEMS Product \& Service Company - France). His current research interests are in the field of MicroElectroMechanical Systems (MEMS) and more 
particularly the electrostatic microactuators. His works are mainly focused on modelling of the energy transduction mechanisms at the MEMS interfaces.

Fifth Author: Marc BERTHILLIER has received an engineering degree from the Ecole Centrale de

5 Nantes, France. He has been engineer at SNECMA, France. He is presently professor in mechanics at the University of Franche-Comté in Besançon, France. His research interests include turbomachinery analysis and modelization of CMUTs. 